

\section{DOIS JOÕES E O CARRO DE BOIS: INTERVENÇÃO ARQUITETÔNICA NA PAISAGEM CULTURAL DO SERTÃO BRASILEIRO}

\section{Luís Antônio Jorge}

Arquiteto e urbanista. Professor Doutor, Departamento de Projeto. Faculdade de Arquitetura e Urbanismo. Universidade de São Paulo

\section{RESUMO}

O artigo é uma breve apresentação do projeto arquitetônico da Casa da Cultura do Sertão, uma intervenção em patrimônio histórico que partiu de uma pesquisa sobre cultura imaterial do sertão brasileiro, na região do Alto do Rio São Francisco, no Estado de Minas Gerais. Tomando o carro-de-bois como de objeto de estudos e engenho emblemático e representativo da cultura local, desenvolveu-se um método de abordagem da realidade do lugar tendo a literatura como guia, precisamente, a obra do escritor brasileiro João Guimarães Rosa.

Palavras chave: patrimônio, projeto arquitetônico, cultura imaterial, Minas Gerais 
ID_PESQUISAS

\section{RESUMEN}

El artículo es una presentación del diseño arquitectónico de la Casa da Cultura do Sertão, una intervención en el patrimonio histórico que resulta de la investigación sobre la cultura inmaterial del interior de Brasil, en la región de Alto do Rio São Francisco, en el estado de Minas Gerais. Tomando el carro-de-bois como objeto de estudio y artefacto emblemático y representativo de la cultura local, hemos desarrollado un método de acercamiento a la realidad del lugar a través de la literatura, concretamente la de la obra del escritor brasileño João Guimarães Rosa.

Palabras clave: patrimonio, projecto arquitectónico, cultura immaterial, Minas Gerais

\section{ABSTRACT}

The article is a presentation of the architectural design of the Casa da Cultura do Sertão, an intervention in historic heritage that results of research about immaterial culture of the Brazilian hinterland, in the region at São Francisco River, in the state of Minas Gerais. Taking the carro-de-bois as object of studies and emblematic and representative artifact of local culture, we developed a method of approach the reality of the place having the literature as a guide, precisely, the Brazilian writer João Guimarães Rosa's work. 
O vaqueiro Pedro Franciano: Eu acho que ele queria era ficar sabendo o tudo e o miúdo. O vaqueiro Tadeu: Não gente, minha gente: que não era o-tudo-e-o-miúdo...

O vaqueiro Pedro Franciano: Pois então? O vaqueiro Tadeu: ... Queria era que se achasse para ele o quem das coisas!

Guimarães Rosa (Cara-de-Bronze)

\section{INTRODUÇÃO}

O poeta João Cabral de Melo Neto conta que seu tio-avô um dia lhe disse que, em Pernambuco, os carros de boi são puxados por duas juntas (ou pares) de bois e no Rio de Janeiro, são puxados por três juntas. Isso o levou a pensar em distinguir as personalidades dos bois de carro, caracterizando os comportamentos dos que vão à frente e dos que vão atrás, buscando motivação para um poema que abordaria os tipos de personalidades artísticas nos homens. Os bois de cambão são os que puxam o carro, os de coice são os que o freiam, quando ele está descendo uma ladeira... Manuel Bandeira é um boi de cambão, o Schmidt é um legítimo boi de coice. Sartre é um boi de cambão, o Camus é um boi de coice. Não há superioridade de um sobre o outro... Não é uma questão de valor, mas de approach da realidade ${ }^{1}$.

O escritor João Guimarães Rosa, no seu conto "Conversa de Bois"2, penetra neste universo temperamental dos bois de carro, dando voz e distinguibilidade aos bois: Nós somos bois... Bois de carro... Os outros, que vêm em manadas, para ficarem um tempo-das-águas pastando na invernada, sem trabalhar... Eles não sabem que são bois... Orgulhosos e cientes da sua importância, conviventes com o homem no seu trabalho, os bois vão sendo apresentados, um a um, de acordo com a função que desempenham na condução de um carro.

1 Cadernos de literatura brasileira: João Cabral de Melo Neto. São Paulo, Instituto Moreira Salles. 1996. p. 23. 2 ROSA, João Guimarães. Sagarana. Rio de Janeiro. Livraria José Olympio Editora. 1968. 10a. ed. 
Dois dos mais geniais joões do Brasil observaram o comportamento do boi de carro, dialogando com a cultura e as artes populares onde o boi se faz presença constante: na música, na dança, na literatura ou no artesanato.

João Guimarães Rosa, segundo estes pitorescos critérios cabralinos, foi um genuíno boi de cambão, ou melhor, boi de guia, nome utilizado para este mesmo boi em Minas Gerais. Em sua obra, Rosa elaborou uma geografia fantástica dos lugares do sertão mineiro: ora apoiando-se na paisagem localizável e reconhecível, à guisa de um cartógrafo, ora revelando lugares de memória, onde sua imaginação redesenhava os contornos do visto e do vivido, com palavras que não se limitaram à descrição das coisas e sim a transcende-las, reapresentando-as como signos de algo que requer e solicita decifração.

Identificar esta paisagem cultural na obra de Rosa é aceitar o convite do autor para buscar "o quem das coisas" expressão (im)precisa de quem realizou uma das mais profundas interpretações do Brasil. Opinião corroborada por Willi Bolle ${ }^{3}$ ao analisar o Grande Sertão: Veredas - o romance e obra-prima de Guimarães Rosa, publicado em 1956 - como um dos livros "formadores" do Brasil pela interpretação seminal da nossa realidade sóciocultural nele contida. Bolle exalta a necessidade de descobrirmos a qualidade específica do conhecimento proporcionado pela ficção, em comparação com o dos estudos históricosociológicos. Esta provocação é especialmente estimulante para fundamentarmos o diálogo visado neste trabalho, entre os campos do conhecimento da arquitetura e da literatura: o conhecimento ficcional, a invenção e a criação sobre a realidade dada, palpável, de se pegar ${ }^{4}$, são comuns em ambos, pois fazem coexistir a realidade observada (e portanto, processada, interpretada) e a realidade imaginada (escrita, desenhada, projetada). Para as analogias aqui permitidas, partimos do reconhecimento de que a obra de Guimarães Rosa revelaria um método de abordagem da realidade brasileira, onde a função poética desta literatura assume a tarefa de aprofundar a dimensão interpretativa e significativa da realidade complexa e de difícil decifração.

3 grandesertão.br. O romance de formação do Brasil. São Paulo. Livraria Duas Cidades. Editora 34. 2004.

4 Trecho do poema-homenagem "Um Chamado João", de Carlos Drummond de Andrade, publicado no jornal Correio da Manhã, em 22 de novembro de 1967, logo após a morte do escritor.

Ficamos sem saber o que era João,

e se João existiu,

de se pegar. 
A realização artística é uma forma de sondagem da dimensão indizível da realidade: a escrita poética ou, mais precisamente neste caso, a escritura roseana revela uma metarealidade, calculadamente distante do real, ao retratar aspectos escandidos de um real lido, reapresentado como reconhecimento e descoberta.

Tendo o conto roseano "Conversa de Bois" como cartografia, traçamos a travessia em busca do "quem das coisas", com especial interesse pela cultura material, pelos artefatos ou coisas construídas para servir o homem na lida da vida. Deste imaginado diálogo sobre o carro de bois entre o poeta João Cabral e o escritor João Guimarães Rosa e, sobretudo, do nosso interesse em documentar ofícios e engenhos do Brasil, formulamos a hipótese de que um carro de bois é um artefato que fala dos temperamentos dos bois e das madeiras. Cabe ainda citar que este interesse pela documentação dos ofícios tradicionais responde à uma conhecida convocação da arquiteta Lina Bo Bardi para que se realizasse, no Brasil, uma ampla pesquisa sobre o artesanato popular ou, nas palavras da arquiteta, sobre a "mão do povo brasileiro"5. Certa vez, Lina, comentando, admirada, o trabalho têxtil dos pescadores na beira do Rio São Francisco, em Propriá, na divisa dos Estados de Alagoas e Sergipe, ela nos convocou: isso não é artesanato nem coisa nostálgica, é coisa do povo, é um convite a um grande levantamento nacional para se pesquisar as nossas verdadeiras necessidades ${ }^{6}$.

Estabelecer relações entre Guimarães Rosa e Lina Bo Bardi, dois dos maiores autores da cultura brasileira da segunda metade do século $X X$, foi uma forma de orientar uma experiência que buscou o confronto entre obra e lugar ou, o diálogo entre literatura e realidade e cultura material, tendo o ofício da construção de um carro-de-bois como objeto de estudo. $O$ carro de bois é um engenho emblemático da paisagem material deste lugar - o sertão retratado por Rosa - onde realizamos um projeto de intervenção em um imóvel tombado como patrimônio cultural pelo Município de Morro da Garça (MG), lugar onde vive o mestre Manuel Alexandre, conhecido construtor de carro de bois, naquela ocasião com 80 anos $^{7}$.

5 A Mão do Povo Brasileiro - título de uma exposição realizada em 1969, no Museu de Arte de São Paulo, por ela concebida e projetada.

6 Depoimento no livro Lina Bo Bardi, S. Paulo, Instituto Lina Bo e P. M. Bardi, 1993, p.203.

72005 


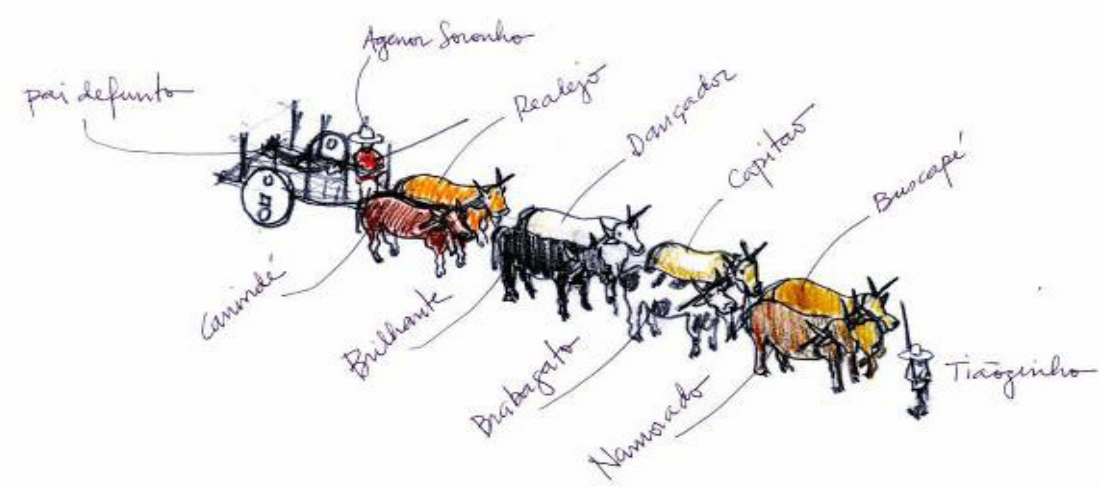

\section{A LEITURA DO CONTO CONVERSA DE BOIS: OS BOIS, AS MADEIRAS E O CARRO}

\subsection{Os bois}

Em consulta aos arquivos do IEB ${ }^{8}$ pudemos constatar que Guimarães Rosa fez uma seleção entre os muitos nomes de bois e de árvores recolhidos no projeto deste conto, demonstrando seu intenso trabalho de pesquisa e elaboração literária. Ao conto: o desenho abaixo serve para acompanhar as falas de cada um dos bois, reconhecendo a sua função na condução do carro. A junta da guia é formada por Namorado e Buscapé, a do coice, por Canindé e Realejo. Estes são os dois pólos antagônicos que definem os temperamentos dos bois, o céu e a terra, a condução e o freio: boi que nasce para guia, jamais será coice. As juntas intermediárias se definem por proximidade a estes dois temperamentos. Habilidades em gestação. Manuel Alexandre, mestre carreiro e construtor, diz que o boi acostuma: o boi velho ensina o novo, para ser guia ou ser de coice.

Vamos, então, aos bois personagens, suas funções e os sinais dos seus respectivos temperamentos, na prosa-poesia de Rosa:

8 No Instituto de Estudos Brasileiros, da Universidade de São Paulo (USP), está o Acervo João Guimarães Rosa que, entre outras preciosidades, guarda suas cadernetas de anotações e originais datiloscritos de seus livros. 


\subsection{Buscapé e Namorado, bois da guia:}

... a dois palmos da sua cabeça, avançavam os belfos babosos dos bois da guia - Buscapé, bi-amarelo, desdescendo entre mãos a grossa barbela plissada, e Namorado, caracu sapiranga, castanho vinagre tocado a vermelho - que, a cada momento, armavam modo de querer chifrar e pisar.

Que santos de grandes, e cheirando forte a bondade, bois companheiros, que não fazem mal a ninguém; criação certa de Deus, olhando com os olhos quietos de pessoa amiga da gente!... E Tiãozinho corre os dedos pelo cenho de Buscapé, e passa também mão de mimo no pescoço de Namorado - imóveis, os dois.

\subsection{Capitão e Brabagato, pé-da-guia:}

Segue seguindo, a ativa junta do pé-da-guia: Capitão, salmilhado, mais em branco que em amarelo, dando a direita a Brabagato, mirim-malhado de branco e de preto: meio chitado, meio chumbado, assim cardim. Ambos maiores do que os da junta da guia.

\subsection{Dançador e Brilhante, pé-do-coice:}

Passo após, a junta, mestra, do pé-do-coice: Dançador, todo branco, zebuno cambraia, fazendo o cavalheiro; e, servindo-Ihe de dama, Brilhante, de pelagem braúna, retinto, liso concolor. Ainda maiores do que os seus dianteiros da contra-guia.

\subsection{Realejo e Canindé, bois do coice:}

E, atrás - ladeando o cabeçalho - conformes, enormes, tão tamanhões o quanto bois podem ser, os sisudos sócios da junta do coice: Realejo, laranjo-botineiro, com polainas lã de brancas, e Canindé, bochechudo, de chifres semilunares, e, na cor, jaguanês.

Vão descer uma rampa de grande declive, e os bufalões destamanhos da junta do coice aguentam o peso do carro, fazendo freio e firmando no chão os cascos, fendidos como enormes grãos de café. 


\section{ID_PESQUISAS}

Em qualquer descida mais pior, era só eu mostrar a vara p'ra os dois, e eles, que são boismestres de coice, iam sentando, e a canga jogando a junta p'ra riba! Por mesmo que as outras relaxassem, estava tudo firme em casa...

A metáfora cabralina ficava cada vez mais clara: as palavras de Rosa tornam vívidos os temperamentos dos bois aludidos por João Cabral na sua tipologia das personalidades

poéticas no âmbito da literatura. Em chave poética, foi possível aprender a observar as sutis diferenças que expressam as maneiras cerimoniosas que o mestre Manoel Alexandre realiza ao conduzir os seus bois aos seus respectivos postos na formação do seu carro de bois. Aos olhos de um observador que não está afeito a este universo, os trabalhos são lentos, ou melhor, aparentemente lentos. Na prática, aprenderíamos que a economia dos gestos é o segredo da rapidez dos resultados.

\section{AS MADEIRAS}

Todas as árvores, em Conversa de Bois, são citadas pelos seus nomes populares. Identificálas nos manuais de plantas arbóreas brasileiras é tarefa quase impossível, pois, no Brasil, são muitas as espécies com as mesmas alcunhas. As características geográficas da região orientaram a primeira seleção que se mostrou insuficiente. Da linguagem científica para exposição literária de Rosa, os nomes das árvores incorporam marcas definitivas, jeitos, portes e formatos que avançam sobre os próprios significados do lugar. Da mesma forma como faz com os bois, a poesia aprofunda a predicação, guiando a nossa viagem de reconhecimento.

Assim, pudemos identificá-las, uma a uma, na ordem em que comparecem no conto:

1 timbaúbas de copas noturnas...

2 braçadas braúnas...

3 jequitibás esmoitados...

4 colher-de-vaqueiro em pirâmides verdes...

5 lanço gigante de um angico-verdadeiro... 
6 paredão dos açoita-cavalos, escuros...

7 enfezadas arvorezinhas: muricis de pernas tortas, manquebas...

8 mangabeiras pedidoras-de-esmola...

9 barbatimãos de casca rugosa e ramos de ferrugem...

10 no raro, um araticum teimoso, que conseguiu enfolhar e engordar...

11 e 12 se, para cantar direito, foi feita de madeira de jacaré ou peroba-da-miúda, tirada no espigão...

A literatura coloca as árvores no lugar, no campo sentipensamental do encontro com o "quem das coisas": as mangabeiras pedidoras-de-esmola são, precisamente, aquelas ali, identificadas no sertão mineiro por um escrutínio tão preciso quanto uma poesia é capaz de ser, ao comunicar uma qualidade que nos fala de tão perto.

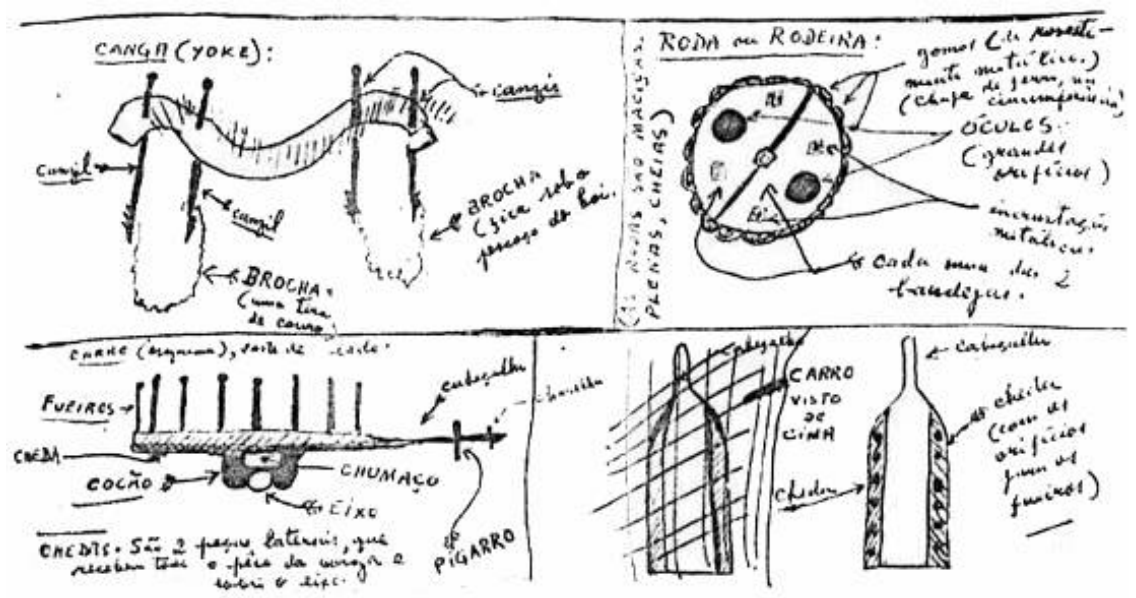


ID_PESQUISAS

\section{O CARRO}

Procedendo da mesma maneira, recolhemos os nomes dos componentes do carro de bois, na ordem em que aparecem no conto:

1 cintas ferradas das rodeiras

\section{2 óculos de tirar barro}

3 tiradeiras

4 argola

5 soga

6 cingéis

7 ajoujo

8 cocão

9 chumaço

10 eixo

11 chaveta

12 cantadeira

13 chifre do unto

14 sedenhos

15 fueiros

16 cheda

17 esteira de caniço

18 vara

19 canga

20 canzis 
21 brocha

22 cilhador

23 pigarro

24 chavelha

25 cabeçalho

26 tabuleiro

27 sola

28 sovela

\section{9 tamoeiros}

30 rodeira ferrada e chapeada nas bandejas

Os nomes dos componentes ou peças do carro, como as árvores, variam de acordo com as regiões do Brasil e Guimarães Rosa estava atento aos nomes utilizados no sertão. Os carros de bois também se distinguem regionalmente, mas, sobretudo, resultam da qualidade dos seus mestres construtores. No inverno de 2005, iniciamos, na Fazenda Capivara, no município de Morro da Garça (MG), uma longa temporada de documentação do trabalho de construção de um carro de bois pelo mestre carreiro Manuel Alexandre, registrando cada etapa, na sua devida época do ano, de fatura de todos os seus componentes e respectivas madeiras nele empregadas. O carro do mestre Manuel é identificado e muito valorizado pelos carreiros da região e leva mais de um ano para ser construído, pois emprega nove tipos de madeira, cada uma colhida no seu tempo justo, na estação adequada, algumas nos meses que tem "r", outras nos meses que não tem "r" no nome. O tempo das coisas é regido por uma plena adesão às lições da natureza. O trabalho no sertão, definitivamente, não obedece aos preceitos e valores da reprodução dos bens (e do capital) típicos da cidade. Trata-se do tempo ditado pelos ciclos de vida e pela natureza das madeiras. Artifícios naturalmente concebidos no tempo do sertão.

Demos início ao trabalho de documentação na época de seca no sertão e o pó da estrada, ainda preso pelo sereno da noite, é ameno e não incomoda aos viajantes extasiados pela 
imagem inédita e grandiosa paisagem do Morro 9 . A família de Manuel Alexandre nos recebe com leite, café e biscoito de polvilho - tudo quentinho para combater o frio da manhã. Ritual que se repetirá, dia após dia, com a simpatia hospitaleira de sempre.

A leitura do Conversa de Bois nos levou à pesquisa sobre um determinado ofício, sobre um saber fazer, um como fazer, com que meios fazer, em inequívoca extinção no nosso país. Queríamos achar o quem-destas-coisas-tão-nossas, este conhecimento capaz de expressar uma chave de leitura do lugar.

A primeira tarefa do mestre Manuel foi o corte do cabeçalho, espécie de espinha dorsal do carro, extraído de um ipê roxo (nessa época, estão todos floridos), criteriosamente escolhido por ele em terra de terceiros. - Eu tenho uma maldição: eu vi um pau d'alho, eu tenho que chegar no pé dele, revela Manuel Alexandre, sobre seu peculiar inventário sobre árvores da paisagem do sertão. Acompanhamos toda a negociação para a aquisição da árvore e que começou com a seguinte frase: Vocês têm um pau que eu tô precisando dele...

O ipê lhe rendeu duas peças a um custo de $\mathrm{R} \$ 300,00$. O cabeçalho, dele extraído, excede os $4,50 \mathrm{~m}$ de comprimento pretendidos para a peça finalizada.

Em seguida, acompanhamos o corte e a montagem das peças que compõem a estrutura da mesa do carro: o cabeçalho, as chedas - atreladas ao primeiro pelas cadeias - e o recavém. As chedas são as duas peças laterais cujas curvaturas devem ser naturais, conforme explica o mestre, ao alertar que não se lavra a madeira para chegar na curva requerida sob pena de comprometer a estrutura e a resistência da mesa do carro (- Um pau de cheda é duro de achar!). Portanto, aquela sinuosa dupla curvatura é reconhecida ainda em estado de "árvore", por um olhar experiente e preciso: há que render duas peças espelhadas, num perfeito sentimento de simetria que vigia a alma de um carreiro condutor. O desenho das chedas é uma marca registrada de um "Manuel Alexandre": alongada, a elipse faz o carro e a ponta do cabeçalho penetrar pela junta do coice, aproximando os bois do carreiro. A colocação das chedas parece fazer crescer o carro e mestre Manuel sentencia, riscando com a unha um lugar preciso onde a curva ideal (numa demonstração de puro sentimento estético) deveria terminar - como quem desenha a elipse vislumbrada na mente.

9 Morro que dá nome ao município de Morro da Garça é cenário do célebre conto “Recado do Morro”, de Guimarães Rosa, publicado pela primeira vez no livro "Corpo de Baile" (Rio de Janeiro, José Olympio, 1956).

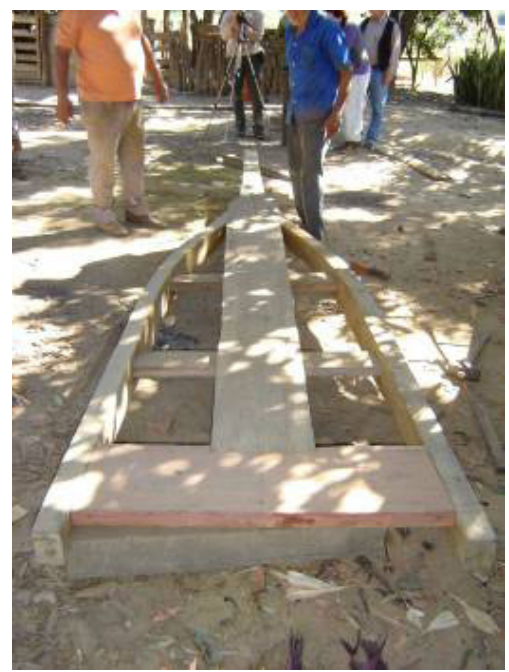

Os componentes principais da mesa: cabeçalho central, chedas laterais, recavém na traseira e os encaixes das cadeias

Desenho de Andrés Sandoval

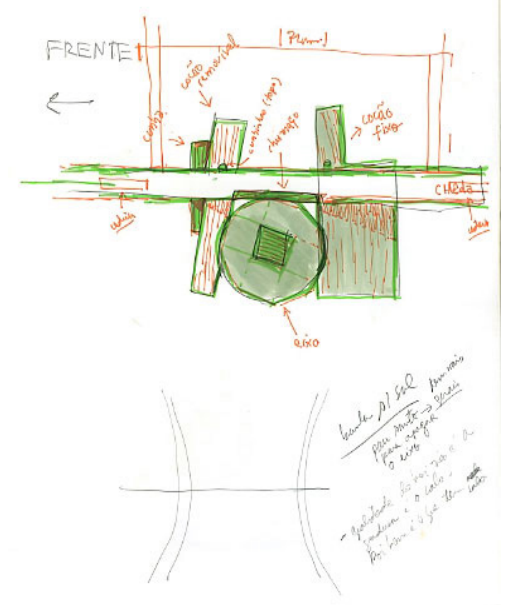




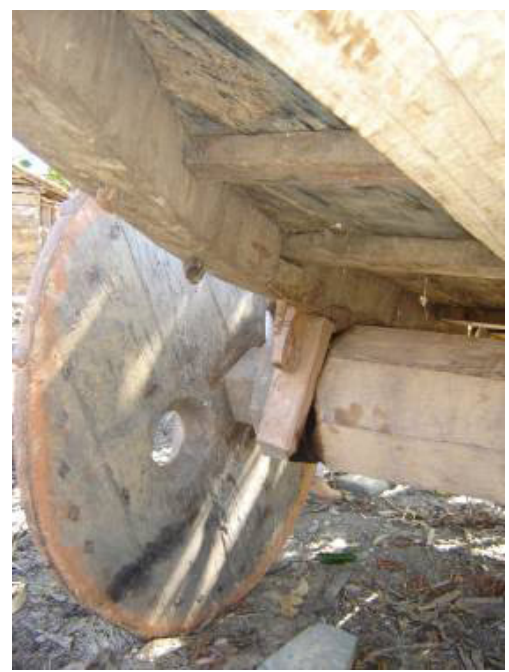

Vista inferior da mesa do carro com o encaixe do cocão no eixo de conexão das rodas. Foto de Luís Antônio Jorge

Desenho de Andrés Sandoval
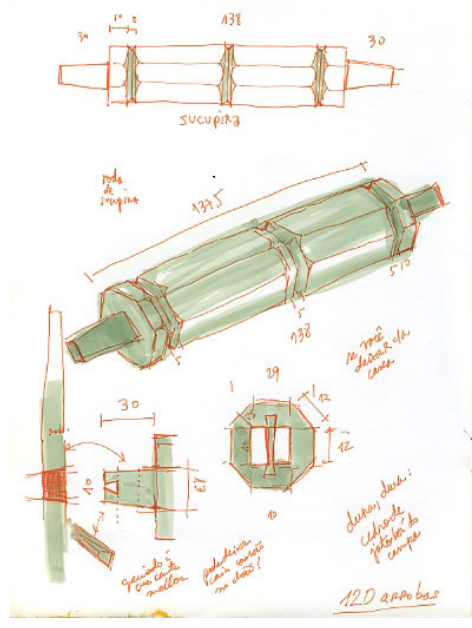

Após uma longa espera pelo tempo das águas, voltamos ao sertão para acompanhar a construção dos demais componentes principais: o eixo, feito de sucupira, e as rodas, feitas de bálsamo. E em seguida, a construção de componentes secundários utilizados para encaixe, fixação e ajustes entre eles e a mesa já construída. São eles: os cocões, o chumaço, os fueiros, a chaveia e o pigarro, além de outros acessórios próprios da amarração dos bois (cangas, canzis, brocha, soga).

Esquema de fixação do eixo na mesa, mostrando os dois tipos de cocões (o fixo e o "cunhado"), ambos feitos de bálsamo, o chumaço, a cheda e os fueiros de marmelo (desenho: Andrés Sandoval).

O cocão encunhado e a marca gordurosa da banha (sem sal) na madeira do eixo. O meião da roda tangencia os óculos, nome do par de furos redondos cuja função é deixar um acesso para retirada do barro acumulado, mas também, oferecer uma saída para o canto do carro, para o som fluir melhor, sendo por isso, construídos de forma a haver um giro de 90 o de uma roda em relação à outra). O Chumaço é a peça do canto do carro que, no do Manuel Alexandre, é feito de pau-terra ou amargoso.

O eixo é oitavado e feito de sucupira e exige muita destreza para manter, em corte cônico, uma linha reta passando pelo centro da peça. Os três rebaixos, dois nas laterais e um no centro, formam um canal circular onde se assentam os chumaços e são chamados de cantadeiras. Mestre Manuel explica que o do centro é que faz o carro cantar grosso (ou grave). Os carros com dois chumaços (só os laterais) só cantam fino (ou agudo). -O chumaço do meio muda a cantiga. Perguntamos sobre a função do canto na condução do carro. Num sei não. Só sei que é assim... O boi não gosta só do canto fino. Mas não sei a explicação... O que faz o carro cantar é o peso. Precisa esquentar, pra cantar...

\section{Guimarães Rosa em Conversa de Bois:}

Tu Tião, diabo! Tu apertou demais o cocão... Não vê que a gente carreando defunto-morto, com essa cantoria, até Deus castigo, siô?!...

Vai botar azeite no chumaço, que senão agorinha mesmo pega fogo no eixo, pega fogo em tudo, com o diabo p'r'ajudar!... 
O cocão removível é feito de bálsamo e untado pela banha (gordura) de porco para o atrito entre as peças de madeira não atear fogo ao carro.

A roda feita em bálsamo é formada por cinco pranchas (com o centro mais espesso e que vão afinando em direção às bordas): o meião e duas cambas (ou cambotas) para cada lado, até formar o círculo. O agulhamento metálico é para enfeitar a roda. Caprichos do ofício. A espiga do eixo atravessa o centro da roda e é presa por cavilha. $O$ anel de metal que reveste a roda é esquentado, dilatado e, quando preso, é rapidamente esfriado com água. Mestre Manoel utiliza um rudimentar instrumento para medir o tamanho do anel metálico que reveste a roda de bálsamo: um conta-giros feito por uma pequena roda metálica presa a um cabo de madeira. Mais uma lição de simplicidade - saber a medida do perímetro, sem relacioná-lo com a medida do raio de um círculo e o número $\pi$.

Carinhoso e Sertão são os nomes dos bois de coice do mestre Manuel que, ajustando a canga do coice e os canzis (par de peças de jacarandá muxiba que trespassam a canga para prender a cabeça de cada boi) diz que um carreiro não ensina o boi, só o aperfeiçoa. $A$ curvatura da canga do coice é diferente da curvatura da canga da guia: aquela permite que o boi ajoelhe para frear o carro e puxar os que vão à frente; esta impede este movimento dos bois e evita que a guia seja atropelada pelos que vêm atrás. Correntes de segurança são presas na canga do coice, atravessam por baixo da mesa e prendem o argolão, quando "a descida é de respeito". A chavelha e a orelha prendem a canga-do-coice e o pigarro para proteger o cabeçalho quando os bois são retirados do carro e ele fica diretamente em contato com o solo. Quando o carro é desengatado, os bois acompanham mestre Alexandre até o lugar da guarda das cangas. Só quando se retira a soga, o boi sabe que está livre. Eles são leais e pacientes e esperam o tempo que for preciso.

\section{A PALAVRA NO SEU LUGAR}

Guimarães Rosa foi um designer da linguagem. A sua imensa obra está marcada por uma poética profundamente comprometida com a invenção do mundo, por meio da ampliação da linguagem, pelo alargamento de fronteiras, sejam cognitivas, sejam sensíveis, isto é, sua escritura promove um intenso intercâmbio entre os nossos sentidos, acionados para alcançar um outro patamar de consciência. 
Ao recuperar a tradição das fábulas infantis onde geralmente os bichos falam, Guimarães Rosa, em Conversa de Bois, apresenta um tema recorrente na sua obra: a comparação entre a linguagem pura, despojada, espontânea, desavisada, "iletrada" - a dos bois - e a linguagem "armada", eivada de intenções retóricas, que caracteriza o mundo dos homens - tudo, pensado, é pior...

O mundo dos bois de carro não está imune ao mundo dos homens, pois são realidades conviventes, mas distintos como Rosa aprecia frisar. O mundo dos homens é o mundo do pensamento que se distancia da natureza das coisas. O mundo dos bois é o mundo espontâneo onde a linguagem e as coisas que ele designa ainda são coincidentes. Esta é uma das lições morais desta fábula, à La Fontaine, que Rosa narra quando retrata o acontecido com o boi Rodapião, um boi dado ao pensamento, demasiadamente humano para um boi:

(...) Só falava artes compridas, idéia de homem, coisas que boi nunca conversou.

(...) Então, boi Rodapião ainda ficou mais engraçado de-todo. Falava: (...) Vocês não fazem como eu, só porque são bois bobos, que vivem no escuro e nunca sabem porque é que estão fazendo coisa e coisa. (...) é preciso pensar cada pedaço de cada coisa, antes de cada começo de cada dia...

E nós não respondíamos nada, porque não sabemos falar desse jeito, e mesmo porque, cada horinha, as coisas pensam p'r'a gente...

Lição moral de uma história que pode ser interpretada como a evidência das limitações do pensamento contido na linguagem diante dos sortilégios da sorte e do destino. O conto narrado aponta para a falibilidade que caracteriza a condição humana, ao mesmo tempo em que observa a sabedoria existencial (de boi) de reconhecer, nas coisas, as suas lições. Engolfados no viver de cada dia, em cada momento encontramos os nossos rumos. Assim, a fala do boi não se basta em si mesma e é sempre menor que a vida. Vida que, no entanto, é susceptível de leitura. Argumento análogo foi apresentado pelo filósofo Bento Prado Jr. na sua brilhante análise sobre a obra de Rosa, onde conclui que... o mundo é um livro e nele está depositada, anterior a toda escrita, uma Escritura primordial que é preciso dizer novamente. Tarefa insuperada da literatura de Rosa. Seriam estas as lições de sua poiesis? 


\section{ID_PESQUISAS}

O mundo redescoberto pela poesia está fartamente disseminado neste conto. Guimarães Rosa oferece pistas, mas nunca explicações definitivas. Vejamos algumas declarações suas sobre a língua e a linguagem, para repórteres de revistas não especializadas:

O idioma é a única porta para o infinito, mas infelizmente está oculto sob montanhas de cinza ...

Escrevendo, descubro sempre um novo pedaço de infinito. Vivo no infinito; o momento não conta ${ }^{10}$.

No Brasil a linguagem ainda não se libertou. Está virgem. Há um campo imenso para explorar, novas formas, maior flexibilidade, maior expressividade. Em suma: é preciso cultivar a expressividade da língua.

Eu não crio palavras. Elas todas estão nos clássicos, estão nos livros arcaicos portugueses. São expressões de muito valor que eu pretendo salvar. Em Sertão: veredas há palavras que nem em Portugal se falam mais. Mas existem. Para determinadas passagens, entretanto, não existem palavras. Então é preciso criá-las, ou redescobri-las através de sons que a correspondam ${ }^{11}$.

Em Conversa de Bois, este exercício de libertação pela poesia já está anunciado com grandeza, riqueza e profundidade. O quem das coisas. Uma poética que domina a palavra em todas as suas dimensões sensitivas - antes de virar significado, a palavra ocupa o espaço sonoro, convidando o leitor a lê-la em voz alta para apreender melhor a paisagem sonora do sertão:

O rechinar, arranhento e fanhoso, enchia agora a estrada, estridente.

Mas o caminho vai. E alongam-se para diante, na paisagem luminosa, as sombras songas dos bois.

Os bois tafulham as munhecas, com cloques sonoros; quando desatolam, para outra passada, a água suja escorre, chorrilhando, para encher os moldes dos cascos, e, no mais mole, as bainhas - as fundas cisternas cavadas pelos mocotós.

10 “Viagens imaginárias - O sertão e as veredas de G. Rosa" - Revista "Manchete", 20.07.1991

11 "Guimarães Rosa fala aos jovens" - Revista "O Cruzeiro", 23.12.1967 
Tranco... tranco... Bate o carro, em traquetreio e solavanco. Mas, no caminho escabroso, com brocotós e buracos por todos os lados, Tiãozinho não cai nem escorrega, porque não está de-todo adormecido nem de-todo vigilante. Dormir é com Seu Soronho, escanchado beato, logo atrás do pigarro.

Ao final do conto, desenha-se o espaço do possível diálogo entre boi e o menino, entre a conversa dos bois e o sonho do menino, pois a linguagem dos sonhos é mais livre, espontânea e natural do que a linguagem pensada. O diálogo entre a fala/pensamento dos bois e o sonho/pensamento do menino-guia expressa a metafísica poética de Rosa, nas palavras de boi:

O bezerro-de-homem sabe mais, às vezes... Ele vive muito perto de nós, e ainda é bezerro... Tem horas em que ele fica ainda mais perto de nós... Quando está meio dormindo, pensa quase como nós bois... Ele está lá adiante, e de repente vem até aqui... Se encosta em nós, no escuro... No mato-escuro-de-todos-os-bois... Tenho medo de que ele entenda a nossa conversa...

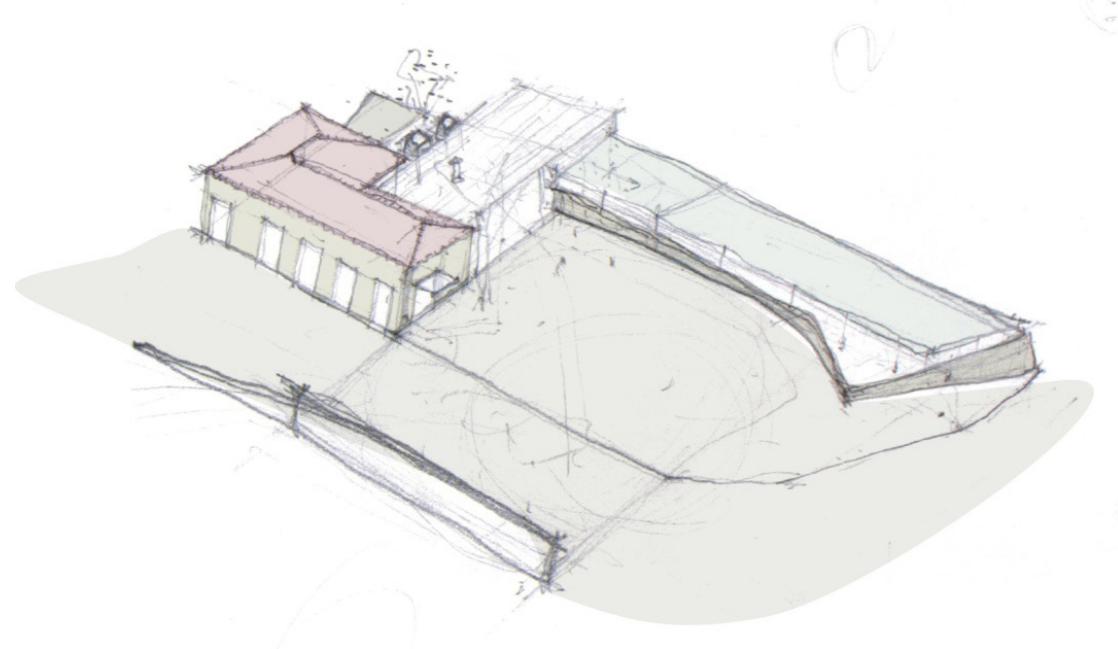


A derradeira lição do conto para o efeito deste trabalho é entender a conversa do mestre carreiro Manuel Alexandre na sua atividade: escolha das madeiras, o fabrico dos componentes do carro, os encaixes próprios dos materiais empregados, as ferramentas, o labor e o tempo de cada etapa, o aprendizado experimental do ofício e das suas técnicas. No mato-escuro de um conhecimento, cabe indagar se este saber não poderá ser empregado em outros objetos ou tecnologias, restabelecendo o elo entre tradição e invenção, vital para o reconhecimento de uma cultura afirmativa, como vislumbrava a arquiteta Lina Bo Bardi.

Este trabalho de pesquisa, documentação e reflexão orientou a elaboração do projeto de arquitetura para a Casa da Cultura do Sertão, construído em 2008 que, sumariamente, apresentaremos a seguir.

\section{A CASA DA CULTURA DO SERTÃO EM MORRO DA GARÇA (MG)}

A Casa da Cultura do Sertão ocupa um casarão tombado pelo município e reabilitado como área de exposição. O edifício fica na área central deste povoado, no caminho de acesso ao Morro que dá nome ao município (Morro da Garça), principal referência na paisagem

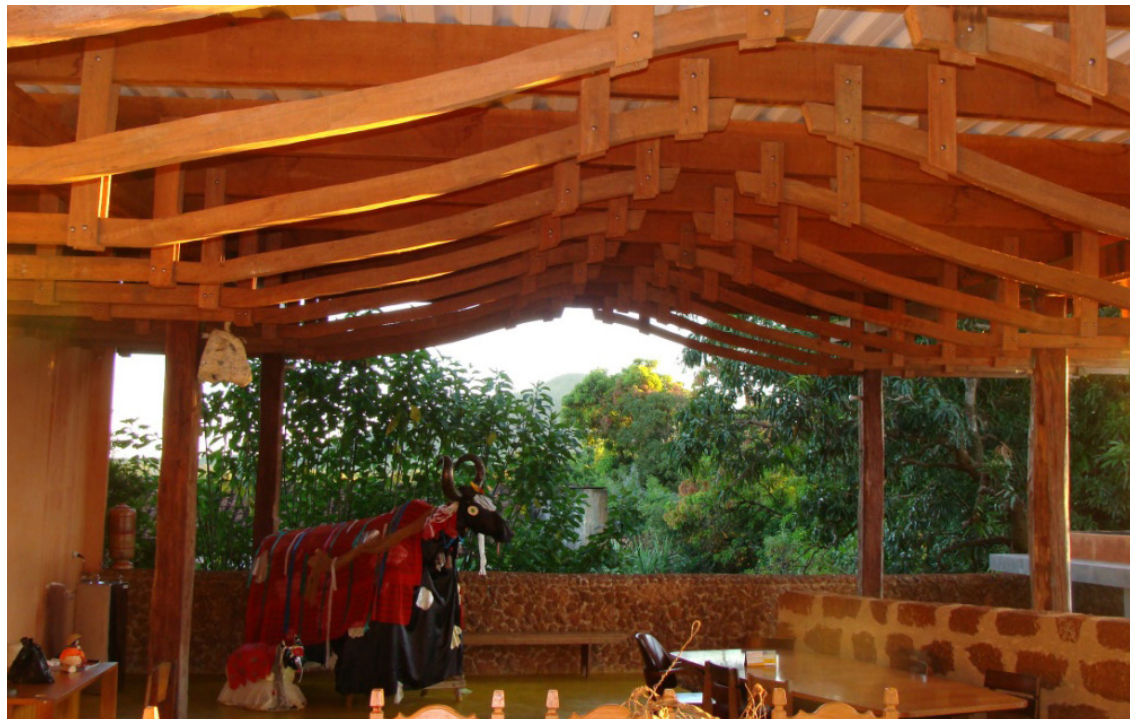

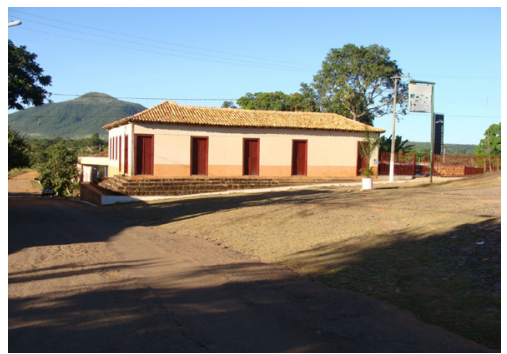

Casa da Cultura do Sertão, com o imóvel tombado à frente e o Morro da Garça ao fundo
A estrutura de madeira que sustenta a varanda foi inspirada nos componentes do carro-de-bois, para enquadrar a silhueta do Morro que aparece ao longe, no horizonte. Foto: Luís Antônio Jorge 


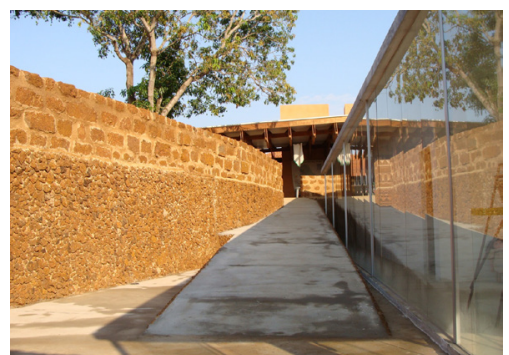

Pavilhão técnico, implantado na cota mais baixa do terreno. Foto: Luís Antônio Jorge

Interior da casa restaurada, com a exposição sobre brinquedos e bonecas tradicionais no sertão. Foto: Luís Antônio Jorge daquela região de Minas Gerais. A pequenina Morro da Garça tem suas origens no século XVII, como parada no caminho boiadeiro que ligava a Bahia até a Vila de Sabará.

O conto O Recado do Morro, publicado pela primeira vez no livro O corpo de baile (1956) de João Guimarães Rosa, faz referência direta a este Morro e a paisagem do lugar:

Lá - estava o Morro da Garça: solitário, escaleno e escuro, feito uma pirâmide.

(..)

E assim seguiam de um ponto a um ponto, por brancas estradas calcáreas, como por uma linha vã, uma linha geodésica. Mais ou menos como a gente vive. Lugares

(..)

Queriam subir, e ver. O mundo disforme, de posse das nuvens, seus grandes vazios.

\section{(..)}

Em cada momento espiava de revés, para o Morro da Garça, posto lá, a nordeste, testemunho. Belo como uma palavra.

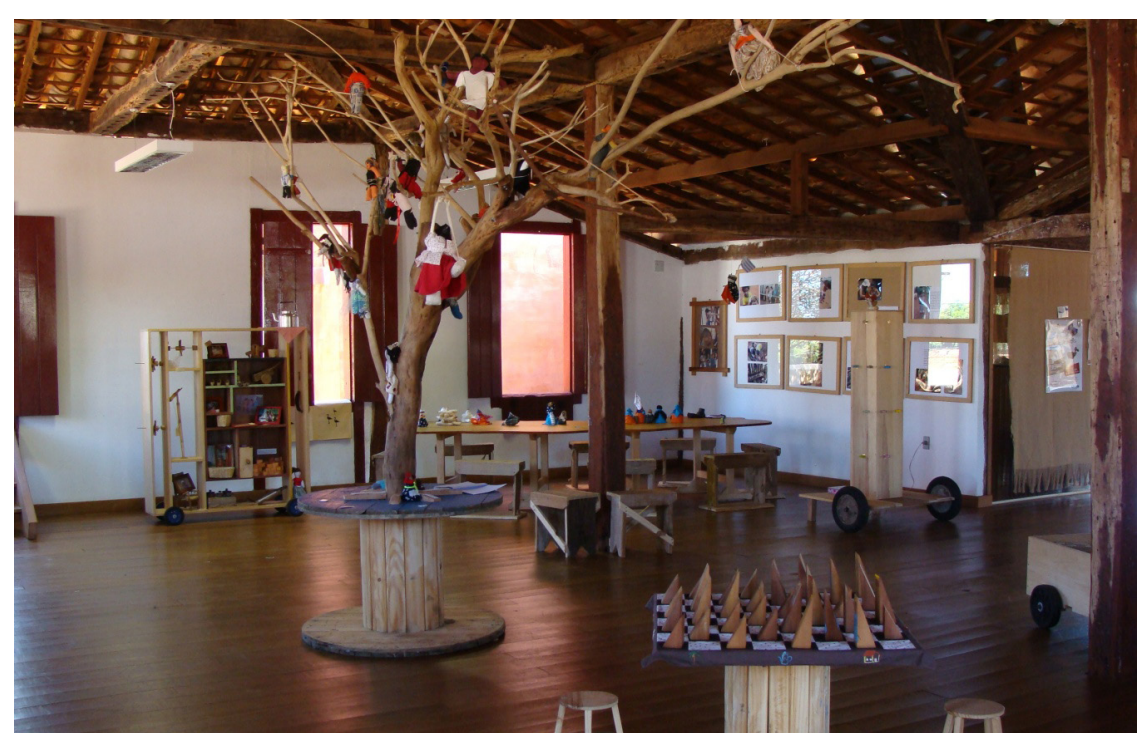


A idealização da Casa de Cultura do Sertão se justifica, em grande parte, por se situar neste Morro, personagem de um dos contos mais celebrados de Guimarães Rosa, fato que tem levado, já há muito tempo, a realização de eventos regulares dedicados ao autor. O projeto responde a estas demandas e serve para expor acervos relativos à cultura local, reunir pesquisadores e promover ações educativas e de difusão cultural sobre o universo do escritor Guimarães Rosa. E cada vez mais, recebe, também, turistas atraídos pelo programa oficial do Estado de Minas Gerais que instituiu o Circuito Turístico Guimarães Rosa.

O projeto elaborou o restauro do casarão, eliminando interferências posteriores que feriam as características originais, mas também propôs novo arranjo espacial interno, conectando espaços segregados. Da mesma forma, realizou ampliações e um anexo. O quintal da antiga casa tornou-se um largo que orienta o acesso principal ao conjunto, feito por um espaço avarandado, onde foi construída uma cozinha caipira. Ele funciona como átrio e elemento de conexão entre o casarão e o novo pavilhão técnico. Foi a partir do conhecimento do processo de construção de um carro de bois que idealizamos a estrutura de madeira - sobretudo, as tesouras - que sustenta essa varanda. A estrutura faz referência às chedas da mesa do carro de bois e forma uma moldura para a silhueta do Morro, uma espécie de homenagem àquele que funciona como um farol, orientando as travessias dos viajantes do sertão.

O pavilhão técnico, de linguagem contemporânea, fica em cota inferior do terreno. O muro de contenção que o protege foi construído com tapiocanga, uma pedra local. O volume possui cobertura ajardinada pelo capim que nasce entre as pedras do calçamento da cidade. O projeto também definiu novo acesso pela rua lateral, a partir da loja que vende produtos artesanais da comunidade. A cobertura da loja é uma extensão do ateliê do casarão, no nível do peitoril das janelas, projetado como um lugar também integrado ao único espaço expositivo ou de encontros e convívio.

Internamente as paredes são caiadas e pelo lado de fora foram pintadas com pigmentos terrosos da região, retomando antiga técnica de pintura a cal. Toda a construção valeu-se da mão de obra e dos materiais locais, sendo alguns, reciclados. A Casa da Cultura do Sertão foi inaugurada com uma exposição denominada Brinquedos para meninos quietos, cujos trabalhos foram fruto de um conjunto de oficinas educativas e artístico-culturais realizadas em várias comunidades da região. Os participantes, na maioria, idosos e crianças produziram brinquedos tradicionais ou inventaram novos brinquedos com os materiais mais singelos disponíveis nos lugares: tudo aquilo que à fantasia é dado ver. 
Casa Cultura Sertão, planta e corte do Projeto Arquitetônico
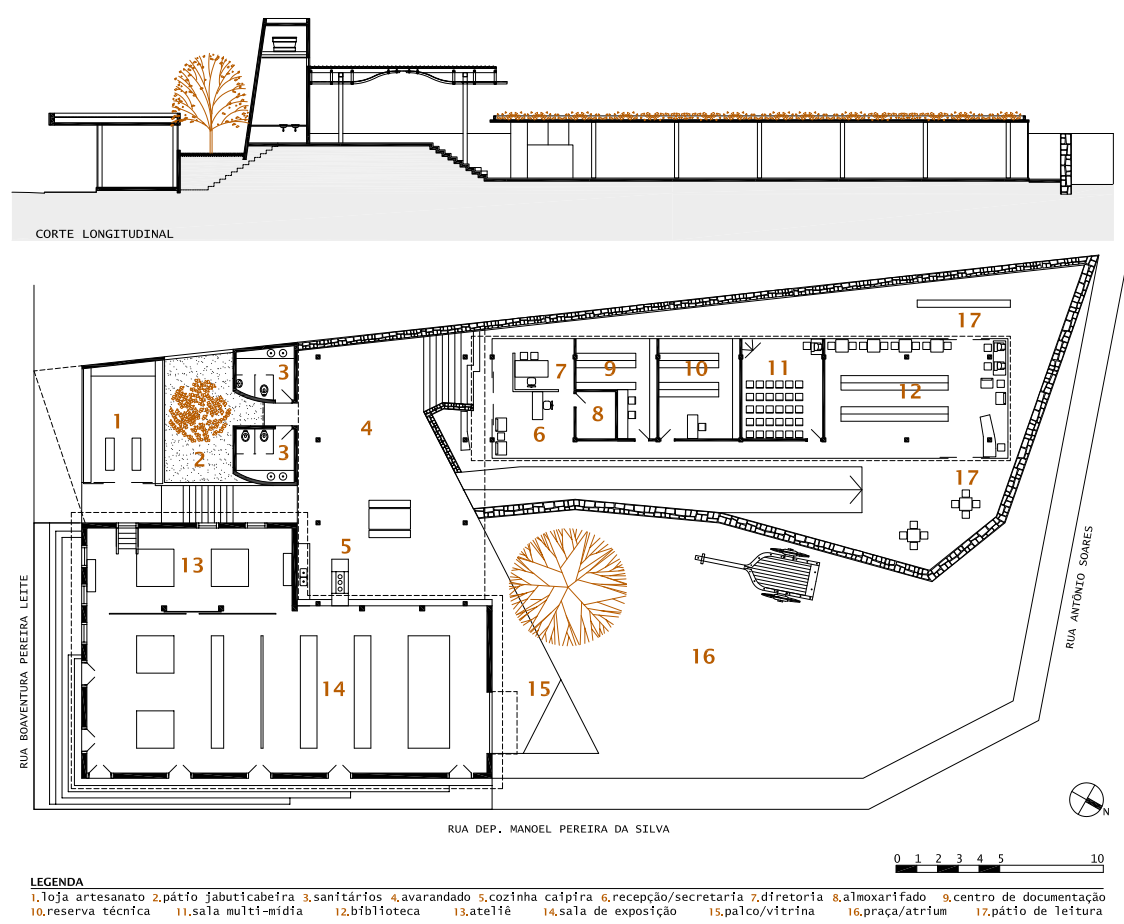

\section{Créditos:}

Pesquisa e Projeto Arquitetônico: Luís Antônio Jorge

Arquitetos colaboradores: Flávia Zelenovsky, Cássio Castro e Pedro Britto 